\title{
Rapid one-of-a-kind product development in a global and virtual manufacturing environment
}

\author{
Y.L. Tu, J.J. Kam and S.Q. Xie \\ Department of Mechanical Engineering, University of Canterbury, Private Bag 4800, \\ Christchurch, New Zealand \\ Email: p.tu@mech.canterbury.ac.nz.
}

\begin{abstract}
This paper reports a computer software platform for rapid product development in one-of-akind production (OKP) in a global and virtual manufacturing environment. The OKP companies in this paper are understood as product oriented manufacturing companies which adopt a market competitive strategy as so-called engineer to order, i.e. design a product according to customer's requirements. Since this research program has been funded by New Zealand government and the most of manufacturing companies in New Zealand are small and middle sized companies, this research has focused its emphasis on the small and middle sized OKP companies. The typical ones in line with this OKP definition are for instance an injection mould/tool manufacturing company (or shop floor), a customised sheet metal product manufacturing company, or a CNC machining shop floor. To shorten the product development cycle time and reduce the cost at same time in these OKP companies, various computer communication and computer aided engineering and management techniques have been applied. To integrate these computer technologies to achieve a rational use of these technologies, we proposed this computer aided product development platform, which is based on a concept of Prototype based incremental product development. This platform consists of a number of computer models and systems/sub-systems. To illustrate the feasibility of this platform, some industrial implementations are also discussed in this paper.
\end{abstract}

\section{Keywords}

One-of-a-kind production (OKP), product data management, rapid product development, virtual manufacturing, and world-wide-web (WWW).

\section{INTRODUCTION}

J.C. Wortmann defined one-of-a-kind production (OKP) by a two dimensions typology. One dimension is determined by a company's production system position strategies, i.e. a product oriented or a capacity oriented. The other dimension is determined by company's market strategies, i.e. make to stock, assembly to order, make to order, and engineer to order. In our research, we focus on the OKP companies which are normally or generally regarded as product oriented and engineer to orders. In fact, many manufacturing companies in New Zealand are small and middle sized and they are competing for discrete customer's orders. In 
short, they are fallen into the definition of this type of OKP companies. To shorten the product development cycle time, this paper will discuss the findings from a research program which aims to develop a computer software platform to integrated all kinds of computer software systems for product development and production management based on the concepts of prototype based incremental product development (Tu1997b) and product production structure which is an integrated data structure for recording and managing the product life cycle data. The main goal to be achieved through this research program is to shorten the lead-time for a product development cycle through integrating various computer software tools, efforts, and data flows, as well as concurrently carrying out the product development processes.

\section{OVERVIEW OF THE PROBLEMS AND PLATFORM STRUCTURE}

According to our study, the major problems to shorten the product development lead-time in these OKP companies include:

1) High customisation. It is obvious that engineer to order will result in a high customisation. High customisation often leads to diversified customer's requirements and hence great uncertainties. These uncertainties give a company numerous reworks, longer product development and production lead time, and high cost.

2) 'Once' successful approach. The production in OKP companies is different from the way in batch or mass production companies. In a batch or mass production company, a prototype of the product will be first made to approve the design and to study the manufacturing processes. In OKP companies, no prototype will be made. The product must be made in OKP companies in one-go, or 'once' successful approach. It is not economic for a mould/tool maker to make a prototype of the mould first and then to make the final mould. It would be ridiculous for a large oil cargo building company to make a prototype of the ship to approve the design and study the manufacturing processes first, and then to make another ship as the final product. They all must make their products according to customer's requirements in one-go. This 'once' successful approach of product production in OKP companies gives a lot of challenges or problems for the companies, (a) uncertainties in product design, process planning and shop floor scheduling, (b) due to aforementioned uncertainties product design and production must be carried out concurrently, or jointly planned and controlled through the whole product development life cycle, (c) hidden costs or reworks resulted by inappropriate or wrong designs, process plan or production schedules, (e) it is difficult (if not impossible) to get a well planned production schedule and inventory plan, and the OKP companies are often running in a fire fighting situation.

3) Looser or Fatter Production Planning and Control. Due to the uncertainties as mentioned above, the OKP companies normally plan their production and allocate production resources in a much looser or fatter way compare with what happens in those batch and mass production companies. In a batch or mass manufacturing company, the production is normally organised along a production line which synchronously moves according to a pre-defined cycle time. 
In a car manufacturing company, for instance, the cycle time may be one to two minutes. This means the production in this car manufacturing company can be synchronised by this cycle time. Operations in every section through the whole plant shall be able to complete in just one to two minutes. In every cycle time, a product (or a car) can be delivered out from the company's final assemble line. This would be impossible for an OKP company. In OKP companies, the production is asynchronous. The operations are loosely planned according to rough estimates of the processes. This loosely planned asynchronous production results in jumble material flows in an OKP company, hence a higher work in process inventory and cost.

4) Continuous customer influence. In OKP, customers may change their requirements through the whole production procedure, which is different from the batch and mass production where the customer's requirements are confirmed or fixed before the product design and manufacture. In OKP, due to a customer's limited knowledge on how to produce the required product, he may change the requirements after the product has been partially made, e.g. when the customer saw the design of the product, a plastic part made by rapid prototyping machine, a part of the product, etc. In a worse case, a customer may wish to change some of his/her requirements or to add some modifications in later stages of production. It is obvious that to be able to cope with this type of continuous customer influence will improve an OKP company's market place.

5) Complicated product data and information flows. An OKP company may produce a number of products at same time. Due to the high customisation of these products, each of these product must be managed individually. It is not rare that a part of product $\mathrm{A}$ is wrongly assembled into product $\mathrm{B}$, a wrong order is placed to the supplier, a wrong inventory is kept in the company, etc. The information and data of product design, process planning, inventory plan and control, and production schedule are made for each of the products and flow simultaneously in the company. On the other hand, no OKP company, particular those small and middle sized, would like to equip itself as a supper company which can meet all kinds of customer's requirements. They often use a lot of partners or subcontractors to compensate their manufacture ability. This leads the complicated product data and information flows not only within the OKP company but also across the companies.

6) Complicated logistics management. This is another problem resulted from the high customisation of OKP. After the discussion of problem 5), this becomes an obvious problem. The complexity of logistics management in an OKP company can be viewed internally and externally. Internally, an OKP company normally has a complicated material handling and inventory control. Externally, it may have an extensive outsource network which consists of complicated supplier chains and partner/subcontractor chains, and a customer network which consists of complicated delivery chains and sale chains.

To solve the problems as mentioned above, OKP companies have been actively adopting advanced technologies, particular those computer technologies, such as intra/internet communication technology, CAD/CAPP/CAM, rapid prototyping, MRPII/ERP (manufacturing resource planning/enterprise resource planning), PDM (product data management), and computer simulation technology. According to a survey (Shaw 2001), these technologies are also widely applied in these OKP 
companies in New Zealand. However, these technologies are often used separately rather than in a systematic and integrated way. The applications of these technologies are lack of system integration and synergy.

To cope with the problems in OKP as mentioned above, a computer software platform for integrating OKP product development processes, data flows and used computer software tools has been developed. The structure of this platform is shown is shown in Figure 1.

As shown in Figure 1, an OKP product development system will include 5 functional systems, viz. Product Definition and Design, Manufacturing Process Planning and Optimisation, Operations Management, Cost Estimate and Optimal Control, and Logistics Management. These 5 systems can communicate externally with outside of the company via Internet Communication Management system, and internally between each other via Intranet Communication Management system (or LAN communication system).

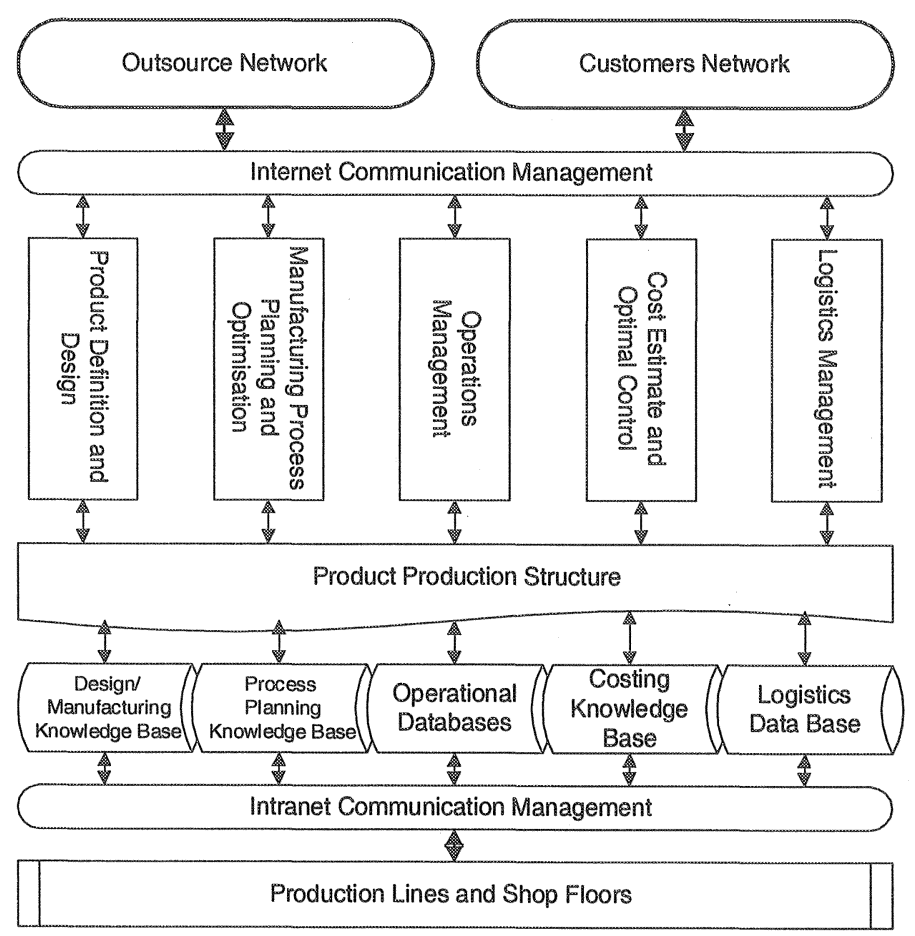

Figure 1 - The structure of the software platform for rapid OKP product development.

Five types of data or knowledge bases are linked to these five systems via LAN communication system. The input to and output from these five systems internally via LAN communication system is a common data object called "Product Production Structure". The product production structure is an integrated product data structure which is written in EXPRESS of STEP (ISO 1994 and 1994E). It hierarchically records all necessary data through a product development life cycle according a product production hierarchy, i.e. Feature level on the bottom of the hierarchy, then Component level, several Assemble levels, and finally up to the 
Product level on the top (Tu 1997a and 1997b). This STEP based product data model provides an integrated data link between various computer systems which are plugged into the overall OKP product development system in a distributed computer network.

\section{PRODUCT PRODUCTION STRUCTURE-AN INTEGRATED PRODUCT DATA MODEL}

As mentioned above, the Product Production Structure of a product records all the necessary data through a product development life cycle. It includes 1) product design data, i.e. geometrical data and property specifications; 2) process data, e.g. tools, fixtures, CNC machine, CNC part programs, etc. for a mould/tool making and manufacturing constraints; 3) Operational data, i.e. manufacturing resources availability, shop floor schedules, and inventory records; 4) Cost data of manufacturing processes (Tu and Xie 2002); and 5) Logistics data. All these data are hierarchically written in an EXPRESS file of the STEP according to the product production hierarchy. A set of computer programming tools, called ST-Developer (STEP Tools Inc., New York, USA) has been used for creating this product data model. The major models of the STDeveloper are shown in Figure 2.

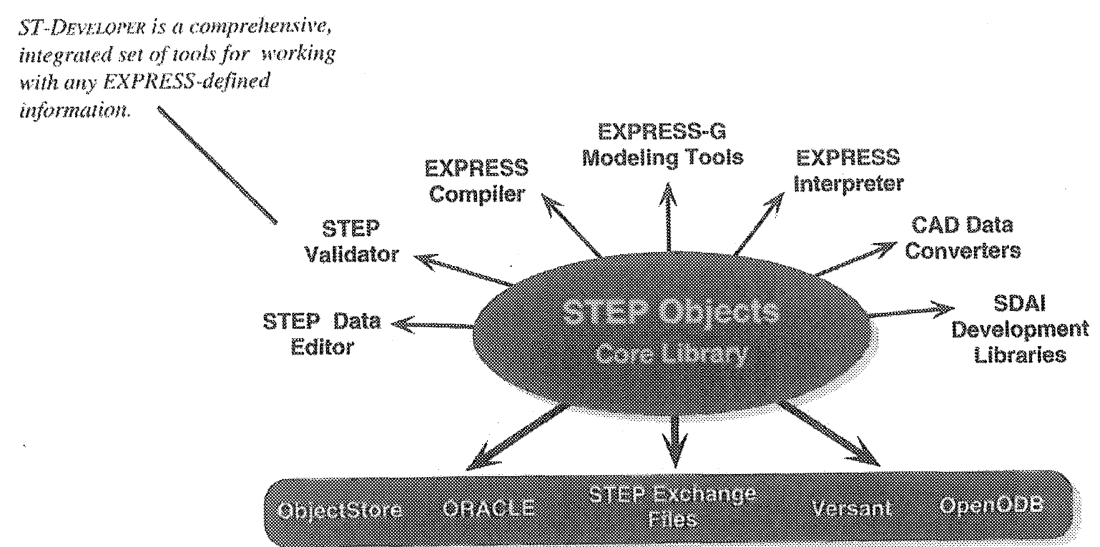

Figure 2 - Functional view of the ST-Developer (after the STEP Tools Inc.)

By using the EXPRESS of the STEP, a geometric shape created by a CAD system can be written as an EXPRESS text file. A right circular cylinder can be expressed in EXPRESS as shown in Figure 3.

In the Product Production Structure, all the data are organised in an object oriented way. If several manufacturing processes are used to create a part feature, these processes and the relevant manufacturing constraints will be part of the Feature class in the EXPRESS file or Product Production Structure. A part may include several features and hence the Part class in the EXPRESS file will include 
these features as its subclasses. A product may be assembled by several parts. Like the part class, the product class will include the parts as its subclasses. Figure 4 shows a feature class, which is a part of the Product Production Structure of an injection mould for moulding parts with complicated sculpture surface. This feature class includes the manufacturing processes and constraints. By using the product production structure, all kinds of data associated with an OKP product development will be integrated managed and stored in a common object. Based on this common object, we have developed a number of manufacturability assessment models to automatically check a product design from the manufacturability point of view (Tu et al. 1998).

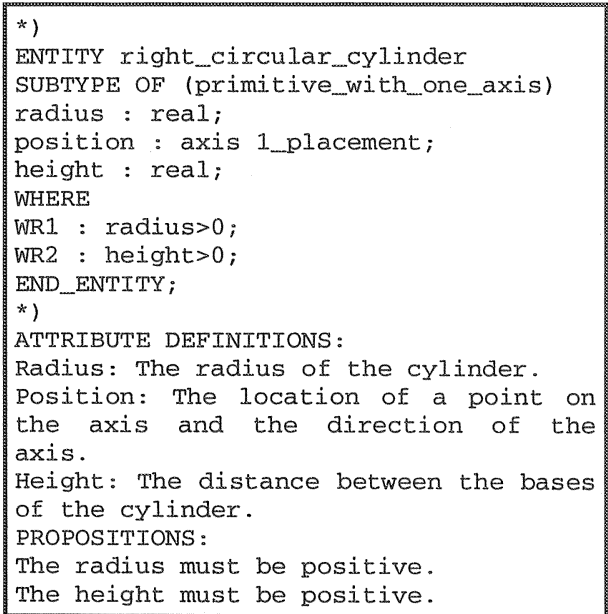

Figure 3 - The EXPRESS file of a right circular cylinder

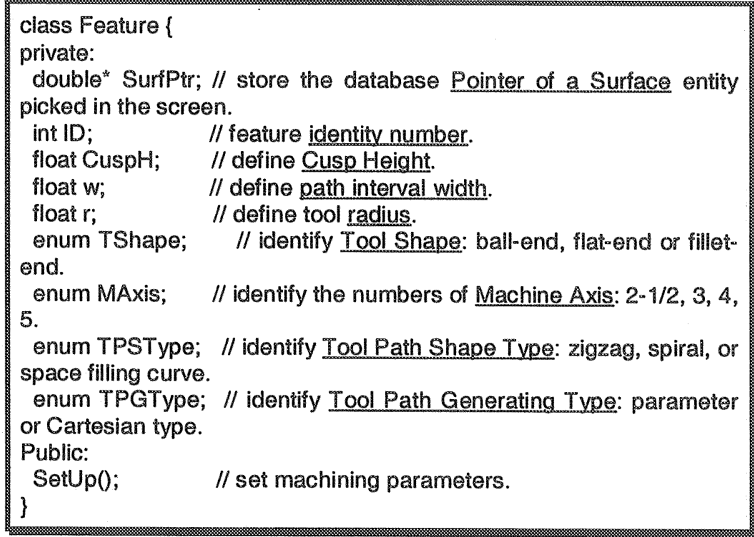

Figure 4 - The Feature class to encapsulate a surface element with machining attributes

All the Product Production Structures of the products will be stored in the Design/Manufacturing Knowledge base to be re-used for future new product design and planning. This will be further discussed in the following section. The screen 
print of this Design/Manufacturing Knowledge base management system is shown in Figure 5.

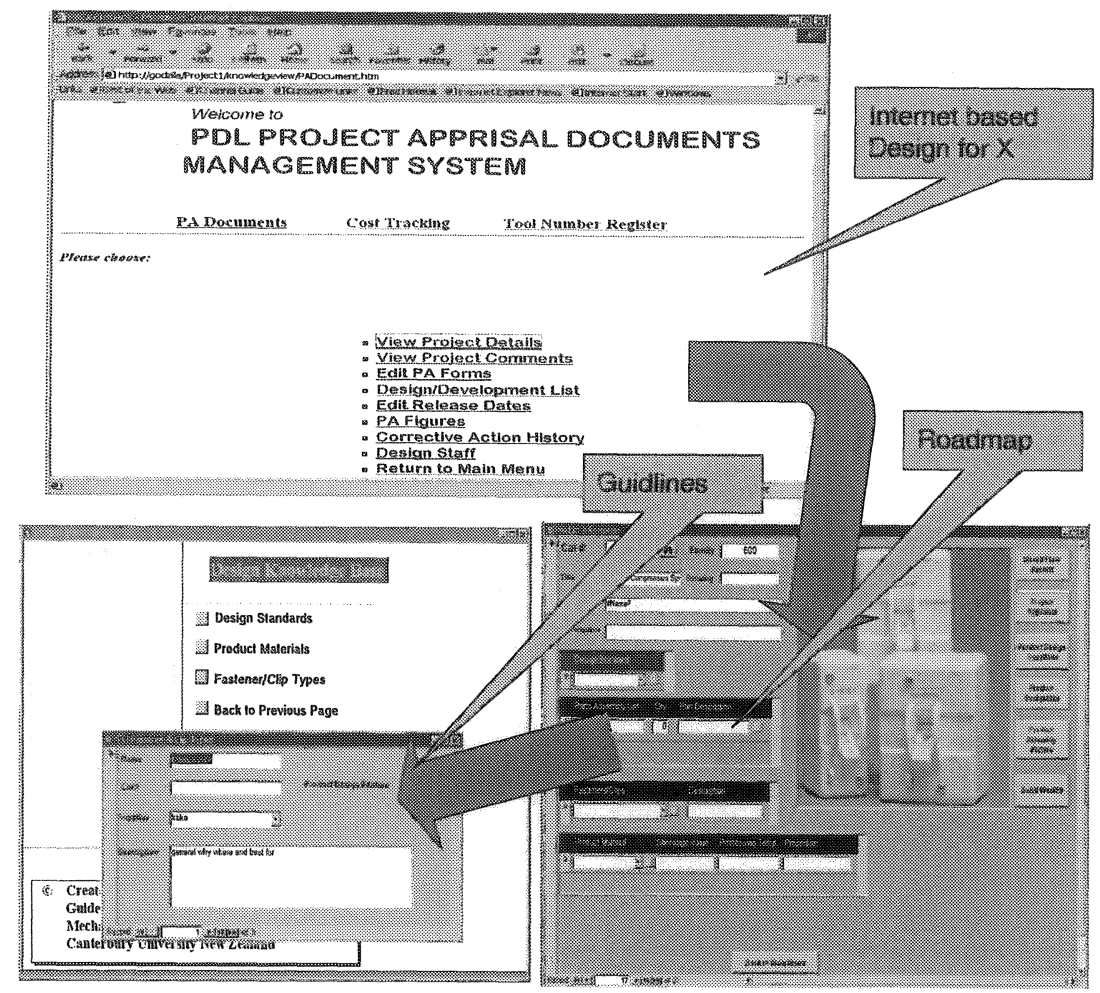

Figure 5 - The Design/Manufacturing Knowledge base management system

It can be seen from Figure 5 that this knowledge base management system has interfaces with Intra/Internets. Hence the Design/Manufacturing Knowledge base can be accessed by all the systems of the OKP management system as shown in Figure 1. Figure 5 shows parts of the Product Production Structure of a type of industrial switches. To manufacture these switches, a plastic injection mould need to be made to mould the plastics shells of these switches.

\section{PRODUCT DEFINITION AND DESIGN}

The Product Definition and Design system mainly converts customer's requirements into a product design, i.e. an engineering drawing plus product property and technical requirement specifications. However, this design system does not work like a traditional product design system which designs a product in one-go. It follows a concurrent engineering principle called "Prototype based incremental product development" to incrementally design a product feature by feature and 
concurrently search or plan all the necessary data for making the designed feature. This concept was first proposed by Tu et al. (2000) for process planning in OKP. Here we would like to further extend the incremental process planning concept into the prototype based incremental product development concept for concurrent product design and manufacturing planning. This incremental product design and planning method is proposed particularly to cope with the high customisation and great uncertainties at the earlier product development stages in OKP. As suggested by this method, the product definition and design will first start with a proper product definition by using quality function deployment (QFD) method to convert customer's requirements into the technical attributes of a product. A computer aided customer interface was developed to automatically convert customer's requirements into technical attributes of a product. A screen print of this computer aided customer interface is shown in Figure 6. It shows converted results from customer's requirements into the technical attributes of an industrial switch.

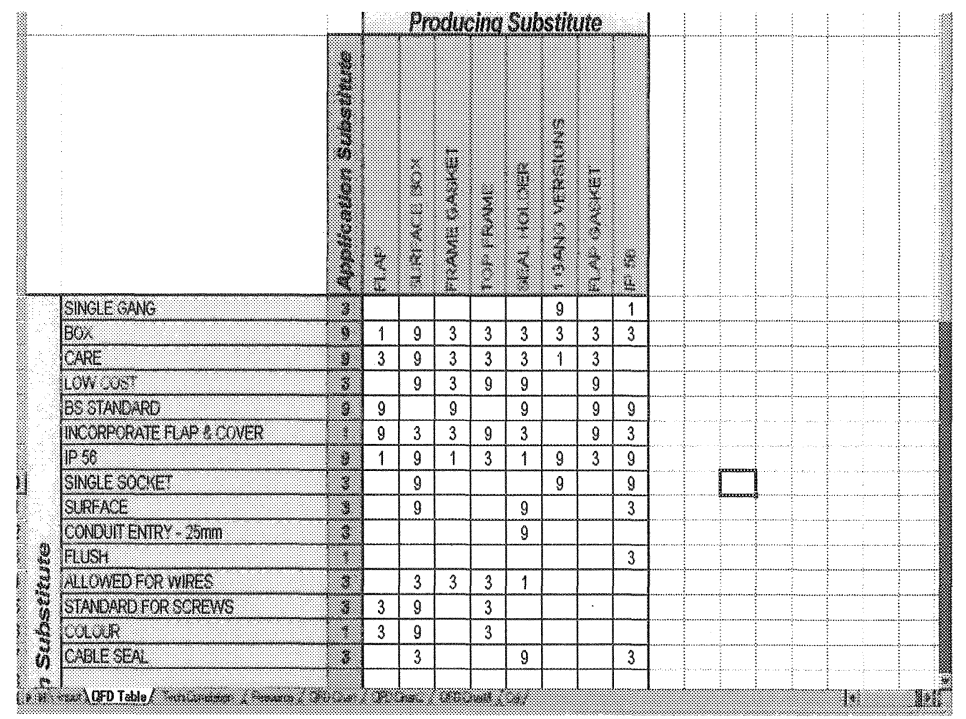

Figure 6 - Screen print from the Computer Aided Customer Interface

Based on the technical attributes, a search model will search from the Design/Manufacturing Knowledge base for prototypes for making the new product. The prototypes are products which were made in the history and are similar to the customer's requirements or the new product. As mentioned in previous section, the Design/Manufacturing Knowledge base stores the Product Production Structures of the past-made products. After the prototypes were searched, a product designer, by using a CAD system, e.g. ProEngineer, can modify these prototypes feature by feature according to the customer's requirements, which are expressed in the technical attributes. These prototypes are also useful to further identify the customer requirements since these past made products can give the customers direct views about what they want. After a feature is modified or designed, the necessary down stream manufacturing and management activities need to be planned to reduce the uncertainties and possible reworks. According to the experiences gained from OKP 
industries, this method helps these companies to reduce the reworks and hence the product development cycle time and costs.

\section{MANUFA CTURING PROCESS PLANNING AND OPTIMISATION}

After a feature was modified, the Manufacturing Process Planning and Optimisation system will search for suitable manufacturing processes from a GT (group technology) code index manufacturing process knowledge base or plan the processes through computer simulation technology or shop floor test if the processes cannot be found from the Design/Manufacturing Knowledge base and Process Planning Knowledge base (Tu et al. 2000). The Process Knowledge Base stores the key manufacturing processes in a manufacturing company, e.g. special surface treatment processes, special jigs and fixtures, special cutting tools, etc. in a mould/tool making company. As discussed in this paper, a Product Production Structure of a produce will include all the data through a product development cycle. It is obvious that the Product Production Structure of a prototype consists of a process plan for making this product in the history. Hence the process planning is in fact to modify one or more process plans of the prototypes into a process plan for making the new product according to the features modifications or designs. If a feature is modified from the original in a prototype, the relevant processes will also be modified from the Product Production Structure. If a new feature is designed, the new processes need to be inserted into the process plan of the prototype. This incremental process planning method was presented by Tu et al. (2000). Besides the process planning activities, the Process Planning and Optimisation system also optimises some manufacturing processes, e.g. $\mathrm{CNC}$ tool path planning to achieve a minimum machining time, nesting optimisation to minimise the trim loss of sheet metal cutting, etc. These optimisation models will be developed according to the particular needs of a manufacturing company. In manufacturing process planning, it is a common case that alternative processes may exist for creating a feature of a part. Under this circumstance, the Process Planning and Optimisation system will write all these alternative processes in the Product Production Structure, i.e. product data model. To select among these alternative processes and to refine the final product data model (or Product Production Structure) will be decided by the product developers according to the cost estimates of these alternative processes to be provided by the Cost Estimate and Optimal Control system, manufacturing resources availability provided by the Operations Management system, manufacturability provided by the Process Planning and Optimisation system itself, and the logistics cost and feasibility to be provided by the Logistics Management system.

\section{OPERATIONS MANAGEMENT}

The Operations Management system will provide the information on production schedule, manufacturing resource availability or plan, and inventory of the raw 
materials or/and components, which is needed or relevant to a manufacturing process as planned by the Manufacturing Process Planning and Optimisation system. It should be pointed out that the Operations Management system manages the necessary manufacturing resources and materials not only inside a manufacturing company but also from the company's suppliers, partners and subcontractors via the Logistics Management system. The data managed and provided by this system is in a global manufacturing environment. These global operations management data will be added into the Product Production Structure as a part of the product data model together with the designed feature and planned manufacturing processes. This system consists of mainly the MRP II (manufacturing resource planning) or ERP system and a number of data interfaces to retrieve the Product Production Structure and to communicate with other systems.

\section{THE LOGISTICS MANAGEMENT}

The Logistics Management system consists of a data base called 'Logistics Knowledge Base' to record all the necessary data of the company's customers, suppliers, partners, and subcontractors, such as their addresses, special requirements, products or services, prices, delivery times, quality/reliability/reputation (measured by 'Excellent', 'Good', 'Average', and 'Poor'), manufacturability (e.g. special equipment, unique experience or process, special surface treatment, etc.), and transportation means and costs. This Logistics Knowledge Base can be accessed and retrieved via intra/internets ( $\mathrm{Tu}$ and Xie 2000b). In addition to this knowledge base, the Logistics Management System also consists of an 'Inquiry and Quotation' process model, a web page management model and an automatic Email sending, receiving and processing model. The 'Inquiry and Quotation' process model can be used to formulate an inquiry on the company's web page for purchasing a material, component, or a manufacturing process from possible suppliers, partners or subcontractors in global. It directly link with the Logistics Knowledge Base. Through opening part of the Logistics Knowledge base to the public, the possible customers, suppliers, partners or subcontractors can directly 'write' their responses into the Logistics Knowledge base, which can be further sorted and processed by the Inquiry and Quotation process model to select the best supplier, partner or subcontractor to meet a customer's requirements. The web page management model is used to manage the company's web page. The automatic Email sending, receiving and processing model manages and controls the company's communications with its suppliers, partners, and subcontractors. Normally, these Emails are in a standard format, which looks like a data table but with hyperlinks. They will be automatically processed by the model and the necessary data will be extracted from these reply Emails, such as company's names and detailed addresses, costs/prices of the materials or processes, delivery times, transportation means, sample products or past works (in forms of electronic photos or engineering drawings) to show their ability to provide a wanted component or manufacturing process, etc. These logistics data will be added into the Product Production Structure together with the feature, manufacturing processes, and operations management data. 


\section{THE COST ESTIMATE AND OPTIMISATION}

The Cost Estimate and Optimal Control system consists of a Cost Index Structure, cost estimate model based on two cost estimate methods, a Costing Knowledge base and a cost optimisation model based on dynamic programming technique and computer simulation technology (Tu and Xie 2002). This system can automatically estimate costs of these modified or designed features and make cost optimisation as a supporting decision for selecting alternative manufacturing processes, resources and suppliers.

\section{VIRTUAL ONE-OF-A-KIND PRODUCTION (OKP)}

The virtual OKP means to apply virtual manufacturing technology in OKP management and control. The virtual manufacturing concept is understood here from two aspects, i.e. a global outsource network as shown in Figure 1 and application of computer simulation technology. The outsource network as mentioned before is used to compensate the manufacturability and improve the flexibility of an OKP company. This is close to the virtual manufacturing definition made by Rolstadås (1994). He defined "a virtual manufacturing company consists of a number of units geographically dispersed but managed as one total unit although the subunits may be under separate management." The reference OKP management system framework as shown in Figure 1 provides particular considerations for a virtual OKP company's needs on Internet communication, global collaboration and manufacturing management. The virtual manufacturing concept is also understood as the application of computer simulation technology in the world (See web sites www.isr.umd.edu and www-cape.cem.eng.osaka-u.ac.ip). To overcome great uncertainties in OKP product design, process planning and shop floor scheduling, some computer simulation packages have been used in our research to develop virtual CNC machines and manufacturing shop floors as test beds to approve alternative designs, processes, and production schedules, as well as the cost estimate tools. Figure 7 shows a virtual horizontal $\mathrm{CNC}$ milling centre which was developed by the Deneb Inc. through using the Virtual NC (Deneb Inc., Dayton, OH) simulation package.

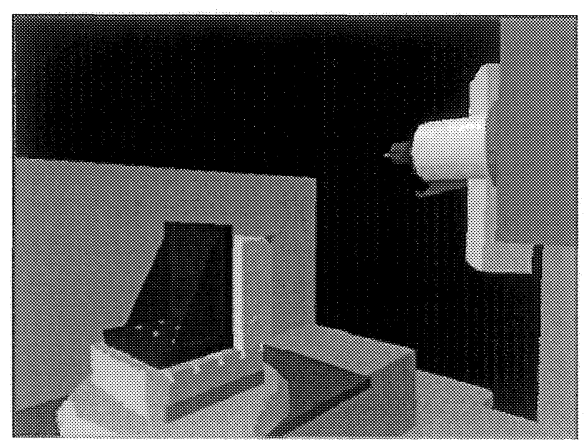

Figure 7 - A virtual CNC milling centre developed by Virtual NC 
Virtual NC is a 3D simulation package. A CNC machine and the part to be machined can be modelled by 1: $13 \mathrm{D}$ models. The simulation package can simulate the machine kinematics and the $\mathrm{CNC}$ controller. After the simulation model is developed, a user can directly send the $\mathrm{NC}$ part program to the virtual $\mathrm{CNC}$ machine and machine the part like it does in a real CNC machine. The Virtual NC has a limited 3D CAD model by which a user can draw a part or a machine. However, by using its importing function, a 3D model which was developed by using a CAD system (e.g. ProEngineer) can be directly imported into the simulation system. The Virtual NC offers the user friendly and object oriented programming languages to build a machine's kinematics model and $\mathrm{CNC}$ controller. It also includes a number of common CNC machine simulation models in the package. By a Virtual CNC machine developed by the Virtual NC, some design alternatives can be approved from the manufacturability point of view, e.g. a cavity with complicated sculpture surfaces in a mould design. Figure 7 shows a press die is machining in the virtual $\mathrm{CNC}$ milling centre.

Besides virtual CNC machines, virtual manufacturing shop floors were also developed by using the QUEST (Deneb Inc., Dayton, OH) simulation package. Figure 8 shows a virtual mould/tool making shop floor, which is a simulation model for the injection mould, press die and tools making shop floor in a New Zealand manufacturing company?.

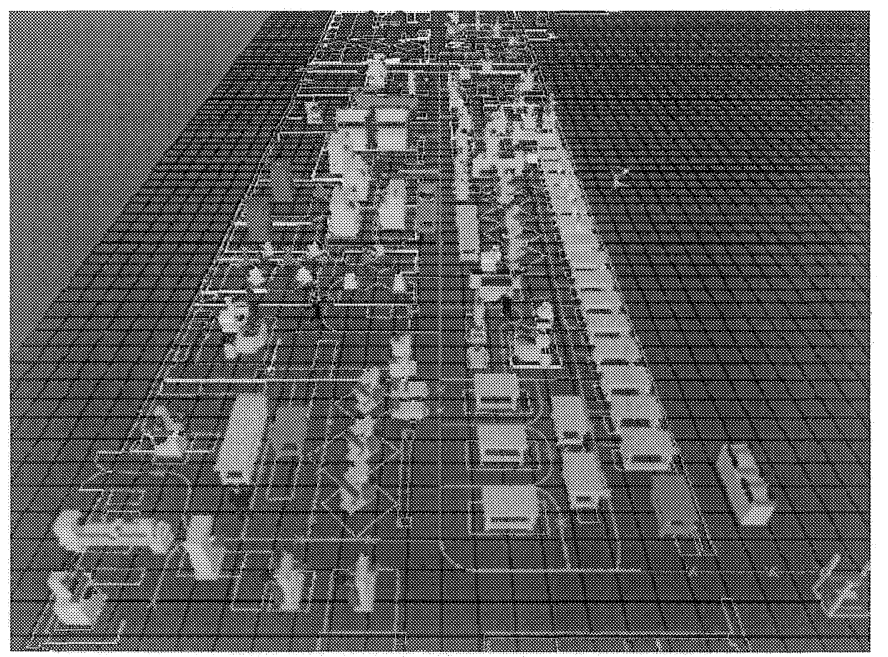

Figure 8 - A virtual mould/tool making shop floor

Like the Virtual NC, the QUEST is also a 3D shop floor simulation model. All the machines and facilities in this virtual shop floor are drawn according to their original geometries in the real shop floor. The machining times for various machining processes are estimated by machining these parts in virtual CNC machines which were modelled by using Virtual NC. The humans' working times and moving speed are quoted according to statistic results. By using this simulation

${ }^{9}$ PDL Industries Ltd., Christchurch, New Zealand. 
model, different production plans and scheduling strategies can be tested. The operation cost for making a mould or a tool can be more accurately got from this simulation model. The company can use this virtual shop floor as a production planning and scheduling tool to avoid the looser or fatter production schedule according as they did in tradition according to rough time estimates of manufacturing processes.

\section{CONCLUSIONS ANID FUTURE DEVELOPMENTS}

This paper summarised the research efforts to shorten the product development cycle time for the OKP companies in New Zealand. The research program has been funded by the New Zealand government through its PGS\&T (public good science \& Technology) grant (UOC X0005) since 1998. The research program is still under going and the fund has been promised until 2004 on a funding level of nearly NZ $\$ 400,000$ pa. Based on the discussions made in this paper, the major research findings which have been achieved so far from this research program include an extended concept of prototype based incremental product development, an integrated product life cycle data structure called "Product Production Structure", an information platform for supporting the integration of various computer aided engineering and management software tools to concurrently and rapidly developing an OKP product. Through using the concepts, methods and the system as presented in this paper in a manufacturing company in New Zealand, the following achievements have been made: 1) Reduce reworks and avoid repeating a design and process planning for a part or a similar product which was made in the past; 2) The data structure helped the company to facilitate the communications between engineers during the concurrently development of a product, automatically record all the data associated with a product development, discussions between engineers during the product development cycle, particular those discussions made at earlier product design stages, and the operation scheduling and management data. These data, discussions and operational data constitute the knowledge of a company and are very useful for a similar product development in future. 3) Applications of computer simulation technology for manufacturing process and shop floor operation simulation as well as knowledge bases, which were built according to the Product Production Structure, helped the company to save a number of shop floor tests in a new product development. Hence it shortened the cycle time of a product development.

The recent developments on or commercially available ERP (enterprise resource planning) and PDM (product data management) systems have some relevance to the research as presented in this paper. However, they are developed to address the problems. First both ERP and PDM systems are computer aided management systems. ERP system places its emphasis on the inventory and cash flow control in a company. It is an extension of the MPRII (manufacturing resource planning) system through applying the computer intra/internet communication technology. PDM system focuses on the product data flow management in a company. Due to the security reason, it mainly employs intranet communication technology and database technology. Both systems are useful computer software systems and can be part of 
the rapid product development system as presented in this paper. An ERP system, or part of it, can be directly applied to build a logistics management system to support the rapid product development. A PDM system can be used as a file management system in a distributed computer network environment. The different electronic files for a product development can be linked by the PDM system into a virtual common object. This distributed file management function is certainly needed by the system as presented in this paper. In fact we made our own PDM system which was reported in (Tu \& Xie 2000b). However, the PDM system does not provide a function to build a real integrated common object as an example shown in Figure 4 for a new product development. The manufacturability assessment model which was developed by us and built into a CAD (or ProEngineer) system will need these manufacturing process data to approve a design of a feature. Likewise, the models for resource and operation checking will need the necessary operational and resource data to approve the planned manufacturing processes. Hence the product data model, i.e. Product Production Structure which was written in EXPRESS of STEP, will also include these operational and resource data under the class of feature, part, or product. This Product Production Structure is a key component for us to realise the concurrent OKP product development strategy as called "Prototype based incremental product development".

As mentioned early, the research program as reported in this paper is an ongoing research program. As important parts of the rapid OKP product development system, the following developments need to be further carried out:

1) OKP line: As viewed by us, the following problems must be addressed to build an one-of-a-kind production line which can cope with diversified customisations and achieve a high production efficiency at the same time:

a) On-line training: The workers on an OKP line cannot be pre-trained since all jobs are different in a theoretically speaking. Therefore, simple, understandable and effective on-line training method must be developed and provided for the OKP line, e.g. demo-teaching videos, past process reminder, process map, operation guidelines, etc.

b) Material handling and line layout: An OKP line can not be physically built according to a one-way-production-flow line in a batch or mass production shop floor since the material flows in OKP are expected to be diversified. Hence, an effective traffic (or material flows) deployment method together with proper process planning and layout planning method need to be developed for an OKP line.

2) E-salesman or intelligent customer interface: Normally, an OKP company needs to deal a lot of customer inquiries not like a batch or mass product company only needs to deal with a limited number of wholesalers. To improve their capacity and efficiency for those OKP companies to process the customer's inquiries, an Internet based automatic customer's inquiry processing system (or e-salesman) will be needed.

3) Manufacturability modelling and automatic assessment: As discussed before in this paper, an OKP company will need an extensive outsource network (see Figure 1) to compensate its manufacturability to cope with the diversified customers' requirements. To properly select a sub-contractor for an outsourced job is not an easy task due to a large number of similar suppliers available in the world. They often provide their services with different lead-times, qualities and prices. To 
optimally or rationally select a sub-contractor under the considerations of lead-time, quality and price. Therefore the manufacturing modelling and automatic assessment of sub-contactors has been identified as a research problem to be solved in future:

So far, we have done some work to model manufacturability of injection mould/tool making companies. A wider company survey was carried out among New Zealand mould/tool making companies. Further investigations will be conducted in those leading mould/tool making companies in Australia, Singapore, Hong Kong and southern China, which are the possible partners or subcontractors for New Zealand mould/tool making companies. Some computer models and manufacturability survey and assessment electronic media have been made in our laboratory, which will be displayed on our web page in near future.

\section{REFERENCES}

[1] ISO 10303-1: 1994, Industrial Automation Systems and Integration - Product Data Representation and Exchange - Part 1: Overview and Fundamental Principles.

[2] ISO 10303-11: 1994(E), Industrial Automation Systems and Integration - Product Data Representation and Exchange - Part 11: The EXPRESS Language Reference Manual.

[3] Rolstadås, A., (1994), "Beyond year 2000 - Production Management in the Virtual Company," Production Management Methods, IFIP Transactions B - 19, pp. 3 10.Shaw, A., Aitchison, D., Raine, J.K., Whybrew, K., 2001, Use of design tools and methodologies for rapid product development in the New Zealand manufacturing industry. ICED 01, Glasgow. Proceedings of the $13^{\text {th }}$ International Conference on Engineering Design; Design Applications in Industry and Education (London: PEP Publishing), pp $27-34$

[5] Tu, Y L, 1997a, "Real-time Scheduling and Control of One-of-a-Kind Production", the International Journal of Production Planning \& Control, Vol. 8, No. 7, 1997, pp. 701 710.

[6] Tu, Y L, 1997b, "Production Planning and Control in a Virtual OKP Company", the international joumal of Computers in Industry, Vol. 34, 1997, pp. 271 - 283.

[7] Tu, Y L, Yang, W Y and Xiong, Y L, 1998, "A Concurrent Manufacturing Strategy for Producing OKP Products with Complicated Sculptured Surface", The international journal of Advanced Manufacturing Technologies, Vol 14, pp. 93 - 98.

[8] Tu, Y L, Chu, X L, and Yang, W Y, 2000, "Computer Aided Process Planning in Virtual One-of-a-Kind Production", the international journal of Computers in Industry. Vol. 41, 2000 , pp. $99-110$.

[9] Tu, Y L, and Xie, S Q, 2000b, "A WWW-based Integrated Product Development Information Management System", Proceedings of IFAC Symposium on Manufacturing, Modelling, Management and Control (MIM 2000), 12-14 July 2000, Patras, Greece, pp. 445 - 450.

[10] Tu, Y L, and Xie, S.Q., 2002, "Product Development Cost Estimation and Optimization in A Global Manufacturing Environment," to be appeared in the Proceedings of AMPS 2002, September 2002, The Netherlands.

[11] Wortmann, J.C., "Towards an integrated theory for design, production and production management of complex, one of a kind products in the factory of the future", Proc. of 6th Annual Esprit Conference. 